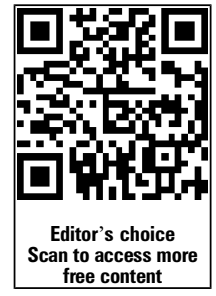

Correspondence to Dr James Morrow, The Dock, 32 Ballydrain Road, Comber, Co Down BT23 5SS, UK; jjimorrow@btinternet.com

Accepted 30 November 2015 Published Online First

27 January 2016
To cite: Morrow J. Pract Neurol 2016;16:162-165.

\title{
Autoimmune limbic encephalitis due to VGKC-Ab. Thanks for the memory. Leo Robin (Title of song, 1937)
}

\section{Jim Morrow}

With the benefit of hindsight, I had probably been unwell for weeks or even months before the worsening of my condition was sufficient for me to allow my wife to finally seek medical advice on my behalf. I can therefore really only directly relate parts of my acute illness as I retain sketchy recollections of this time, so my wife (Sue) has filled in many of the blank bits.

Things were probably first really noticeable when one evening, we were at a concert and I had become acutely confused. Sue became worried when I had not returned after a comfort break. She had to send an attendant to look for me. When he located me, he clearly thought I was intoxicated and we made a hasty retreat back home.

Shortly afterwards on a weekend break to London the same thing happened when, on the third morning, I could not locate the breakfast buffet (even though I had used it the previous two mornings). Then as we disembarked from the plane home later that day, I told my wife that she was in no fit state to drive as she had had too much to drink.... It was $10 \mathrm{am}$.

At this point, Sue finally persuaded me to seek advice from my neurological colleagues (she had been at me for weeks to do so) and one of my colleagues, who was on call that weekend, kindly came out to see me at home that day. He immediately realised that there was indeed something wrong and arranged an urgent MRI. I had this the next day (probably a case of not what you know but who you know). As Sue was driving me home, we got the phone call that no one really wants:

Turn the car around, and get back to the hospital, there is a bed waiting for you.

I was admitted to the neurosurgical unit, primarily because my colleagues did not want me under the scrutiny of my own patients. Early in my admission, I became acutely confused and in the middle of one memorable night (well, not so memorable for me), I rang my wife and accused her of stealing my watch and that I did not know what time it was. Sue was sufficiently concerned to ring the night sister back immediately after I had hung up to say that she was worried about me as I appeared to be agitated and confused. The night sister replied:

I know, he's standing here beside me.

With regard to my investigations, the MRI had revealed bilateral mesial temporal high signal (figure 1) suggesting limbic encephalitis and the electroencephalogram showed paroxysmal epileptiform discharges (figure 2). My initial neuropsychological testing demonstrated irritability, disorientation, poor short-term memory, poor immediate recall, confabulation and lack of insight. Happily, further extensive testing did not reveal any underlying tumour.

The presumptive diagnosis of autoimmune limbic encephalitis was confirmed when my serum anti-voltage-gated potassium channel antibody (VGKC-Ab) returned at a titre above $1000 \mathrm{pmol} / \mathrm{L}$ (normal <100). ${ }^{1-4}$

As stated earlier, I had almost certainly been showing symptoms long before my actual diagnosis. I was struggling at work, feeling tired all the time and muddled at home in the evenings. Being me-and I suspect that this is true of many of us in the medical profession-I had refused to take time off or seek help. Happily (though I know that is the wrong adjective), around this time my wife fell and broke both wrists, forcing me to take some leave and thus allowing me to stay at home to look after her. The rest seemed to help, and I did improve temporarily. I did see 


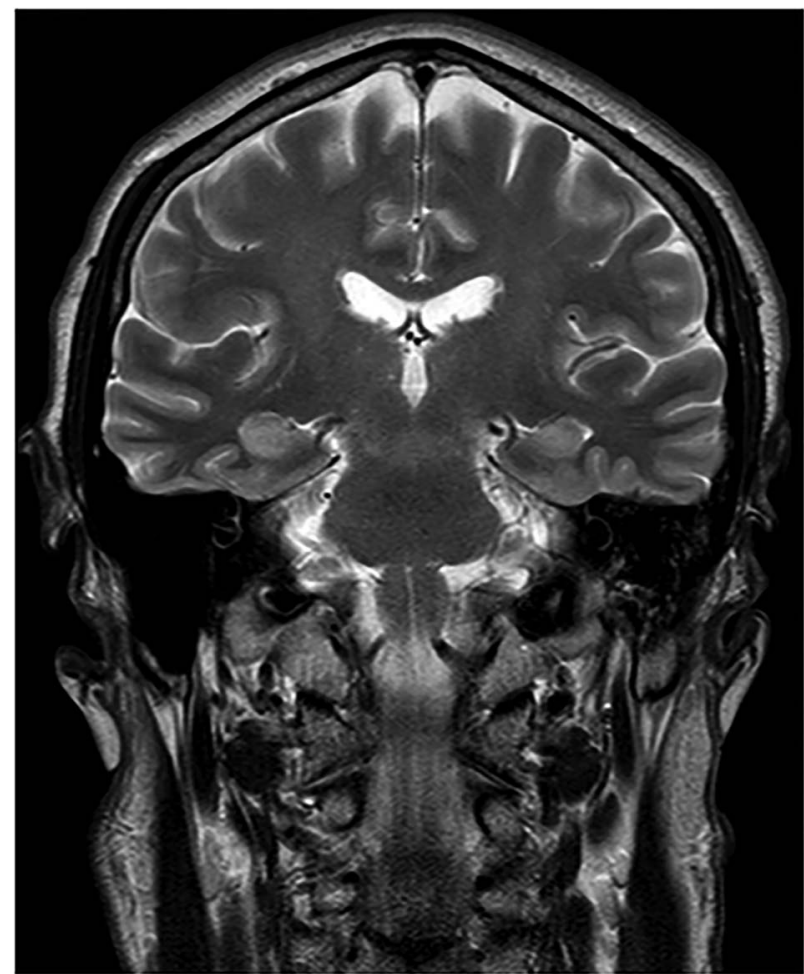

Figure 1 MRI: Demonstrating bilateral mesial temporal high signal.

my general practitioner around this time who prescribed antidepressants.

Again, with the benefit of hindsight, while I was working, seeing patients and driving to clinics, I was probably having intermittent complex partial seizures. At the time, I had no insight or awareness of these (worse still, my epilepsy team did not seem to notice!). Retrospectively, I now believe that it was these that were responsible for some of the fluctuations in my confusion. I referred to these at the time simply as dizzy spells and did actually have a cardiology work-up. Reassuringly, the patient case notes from this time have subsequently been systematically reviewed and no mistakes have been identified.

In hospital I was treated with a course of plasma exchanges, followed by high-dose corticosteroids for immunosuppression and levetiracetam (later changed to lamotrigine, due to mood swings) to control any seizure activity.

Principally, because of the neurocognitive deficits, I was on a prolonged period of leave and have now accepted medical retirement. From a personal perspective, it was this postdischarge period that was most difficult. As insight returned, I realised that I could no longer do the job I had done and loved for over 25 years. I had always been a bit of a workaholic, I had helped establish a regional epilepsy service and I had a number of research projects running, and was, I hoped, a respected member of the neurological community. Now, I was redundant, surplus to requirements and disabled, if not physically (my seizures had seemed to subside), then cognitively. This was a tough time, not just for me but particularly for Sue, who now had me 24/7. She even had to drive me

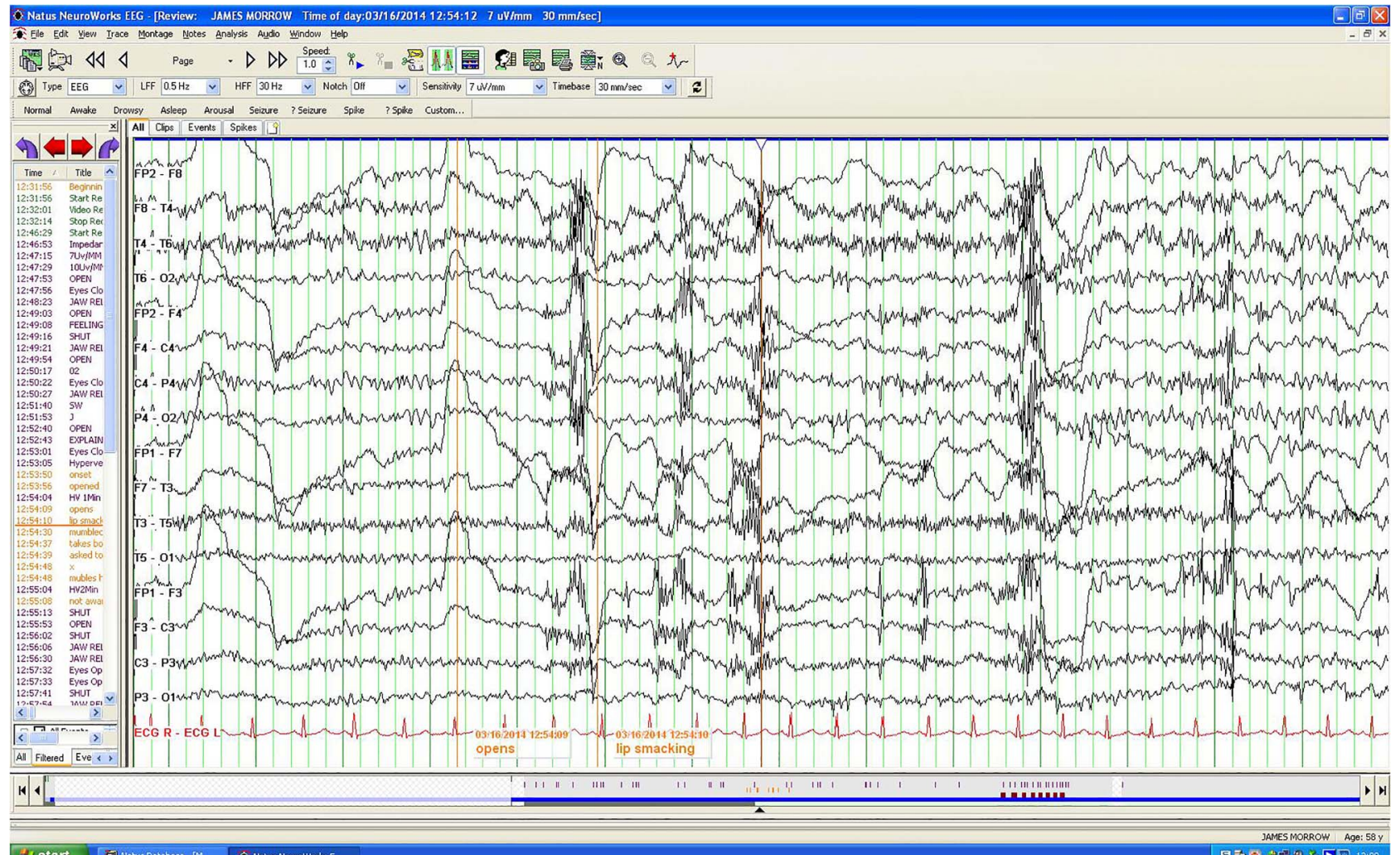

Figure 2 EEG: Demonstrating paroxysmal epileptiform dischares. 
everywhere, as I had surrendered my driving licence, and Northern Ireland has a very poor public transport infrastructure.

I had heard this aspect of illness from so many patients previously. During the acute phase of any illness, there is lots of help and support, but then it is down to earth with a crash. Nobody likes change, and there is no bigger change than a major illness whose effects extend far beyond and far outlive its initial presentation.

However, humans are resilient beasts, and over time - and it was a slow process-I have improved considerably and more importantly adapted to my new life. I was on the corticosteroids for 12 months but have now been weaned off them and remain well with no suggestion of relapse. I have had no further seizures since the early stages of the immunosuppression and 1 year on I have resumed driving, but I have remained on, and will continue on, the lamotrigine.

I have full insight (I think) and I am clear in my thoughts. I am still aware of some memory issues, I can forget people's names for example (but this might just be my age) and interestingly, I sometimes cannot remember a location or how to get to it, not ones that I used or use commonly, that is, not A to B, but ones less frequently negotiated, that is, $\mathrm{Y}$ to $\mathrm{Z}$. I do still also have some holes in my memory for things or places that I have previously done or seen and realise that these may not come back, but happily if I do or go again, I can usually remember it anew this time around, and as they say, it is a whole new world out there. While I really do find the residual memory deficits frustrating, I get by. I do find that if I need to remember something, I now try to write it down or make a list. In fact, the act of writing it actually helps, and often I do not need to refer to the list itself to remember. So often in the past I had counselled patients with memory difficulties to do exactly this, and it actually works! I also have a very understanding group of friends and relatives who, when discussing something we did, premise the discussion with

You'll not remember this Jim, but...

I may have retired from clinical practice and will not return as, although much better, I could not forgive myself if I did and caused injury or hurt to anyone due to an error of judgement. However, I have resumed many of the things that I have always enjoyed (but previously did not always have the time for). I remain committed to the UK Epilepsy and Pregnancy Register, which has helped to define teratological risks associated with individual antiepileptic medication, I am supervising a $\mathrm{PhD}$ student at the University of Ulster and working on new projects there, and recently I have been elected on to the council of the charity Epilepsy Action, where I believe I can add a unique insight as I now know about epilepsy from the inside as well as the outside. I also now have many more and diverse interests, in point of fact it seems there is really not much time off in retirement. I get to the gym at least two or three times a week, I appreciate and collect art, Sue and I have built and cultivate our garden, and I remain a keen, but alas, still a high-handicap golfer. Finally, I have embarked on (another) novel, which must represent some improvement (even if the novel is terrible), as initially I could not even remember the plot, day to day, of books I was reading. The stimulus to the first novel I had published was the tragic death of a very good friend in very unfortunate circumstances. As I believe Aristotle once said, 'tragedy is thus a representation that is worth serious attention'.

One final anecdote. As I can now enjoy life much better than I did previously, I decided finally to have a knee replacement, something I had deferred for a long time. I had suffered a severe knee injury many, many years ago playing rugby and had developed severe osteoarthritis with a valgus deformity, causing me a lot of pain and to limp after increasingly short distances. So I went to see an orthopaedic surgeon. Of course, he panicked a bit regarding my somewhat rare neurological illness and sent me for preoperative checks to a large raft of medical professionals. One of these was a cardiologist.

When I arrived to see him, he greeted me saying:

Don't you remember, Jim? I saw you shortly before your illness. You came to see me because of little episodes you were having and I checked you out then and we ran all the tests and we couldn't find anything wrong.

He referred to his letter at the time.

Jim saw me because of 'dizzy spells' where he said he would suddenly felt unwell, but couldn't really describe the feeling, then he was a bit muddled and disorientated and it took a few minutes for him to regather his wits.

I talked to his wife separately whilst he was having his ECG she said he would suddenly stop whatever he was doing, he seemed to go blank, staring with a glazed expression, be a little pale and not be responsive for about a minute, occasionally he would smack his lips, and then he would seem to come around but be a bit confused for a short time afterwards.

“Mmm," I said, "I think I know what those were...”

\section{Key points}

Immune-mediated limbic encephalitis may be subacute, with a preceding history of several months.

- Limbic encephalitis is not always linked to an underlying tumour.

- Autoimmune limbic encephalitis is treatable and can have a good prognosis.

- Listen to your partner. 
Reviewer's comment from Jane Adcock This is a very interesting, brave and informative description of the author's neurological illness of VGKC-Ab encephalitis. The author's presentation is very typical, so his description is excellent educationally regarding the presentation, diagnosis and management of the condition. More importantly, it documents the patient experience very eloquently. The very honest description of the practical difficulties and the impact on life is a poignant reminder to doctors to really listen to their patients, and highlights that the healthcare system still has little capacity to support patients with long term cognitive sequelae. The author's description of his embracing of the positive and new aspects of his life after the illness, his emphasis of the importance of family and friends, and maintaining life outside of work, is an uplifting conclusion to his unsentimental yet moving manuscript.

Acknowledgements My thanks to the Belfast Trust's Neurology team and especially Drs Stephen Hunt and John Craig who took on what must have been their worst nightmare, looking after me. Also special thanks to Dr Jackie Palace, Department of Clinical Neurology, Oxford University Hospitals NHS Trust for her expert guidance throughout. And of course to my wife Sue who did not sign up to be a carer.

Competing interests None declared.
Provenance and peer review Commissioned; externally peer reviewed. This paper was reviewed by Jane Adcock, Oxford, UK.

\section{REFERENCES}

1 Varley J, Vincent A, Irani SR. Clinical and experimental studies of potentially pathogenic brain-directed autoantibodies: current knowledge and future directions. J Neurol 2015;262:1081-95.

2 Irani SR, Gelfand JM, Al-Diwani A, et al. Cell-surface central nervous system autoantibodies: clinical relevance and emerging paradigms. Ann Neurol 2014;76:168-84.

3 Granerod J, Ambrose HE, Davies NW, et al., on behalf of the UK Health Protection Agency (HPA) Aetiology of Encephalitis Study Group. Causes of encephalitis and differences in their clinical presentations in England: a multicentre, population-based prospective study. Lancet Infect Dis 2010;10:835-44.

4 Thieben MJ, Lennon VA, Boeve BF, et al. Potentially reversible autoimmune limbic encephalitis with neuronal potassium channel antibody. Neurology 2004;62:1177-82. 